\title{
APRENDIZAGEM BASEADA EM PROJETOS NO ENSINO-APRENDIZAGEM DE LÍNGUAS ESTRANGEIRAS ${ }^{1}$
}

Rodrigo CALATRONE PAIVA ${ }^{2}$

Programa de Pós-Graduação em Letras - Universidade Federal do Paraná

RESUMO: O presente trabalho visa apresentar a Aprendizagem Baseada em Projetos (ABP) especificamente no ensino-aprendizagem de línguas estrangeiras, expondo seu histórico e características em contraste com a ABP em outras áreas e na educação em geral. De início, o trabalho apresenta a situação atual de rara pesquisa nesta área no Brasil, o que se compõe principalmente de relatos de como professores organizam seus trabalhos com projetos ou de benefícios que este tipo de trabalho traria para o ensino-aprendizagem de línguas estrangeiras, sem ter, contudo, o tema da ABP como foco principal de suas pesquisas e, talvez por esta razão, não se aprofundarem neste tema (WELP, 2011; KARNAL, 2013; PERUCHI, 2014; TUMOLO, 2015). Além destes, há outros trabalhos que tem a ABP no ensino-aprendizagem de línguas estrangeiras como foco, mas se baseiam em trabalhos que não tratam do assunto especificamente para o ensino de línguas estrangeiras (LEFFA; IRALA, 2014) ou apenas começam a apresentar alguma referência da área (PESSOA, 2006). Então, o trabalho expõe um histórico da ABP e suas características na educação em geral (DEWEY, 1910; KILPATRICK, 1918; HERNÁNDEZ, 1998; ANTUNES, 2001; NOGUEIRA, 2001; FRANCO, 2008; NOGUEIRA, 2008; BENDER, 2014) e depois as características e conceitos no campo especifico do ensino-aprendizagem de línguas estrangeiras, além de seus benefícios para o ensino nesta área na atualidade (FRIED-BOOTH, 1982; STOLLER, 1997; BECKETT, 1999; EYRING， 2001; BECKETT， 2002; FRIED-BOOTH，2002; BECKETT， 2005; BECKETT; SLATER, 2005; BECKETT; MILLER, 2006).

PALAVRAS-CHAVE: Aprendizagem Baseada em Projetos; Ensino-Aprendizagem de Línguas Estrangeiras; Metodologia do Ensino de Línguas Estrangeiras.

ABSTRACT: This paper aims at presenting the Project Based Learning (PBL) approach, specifically in the foreign language teaching and learning field showing its characteristics and historical roots in contrast with PBL in other fields and in education in general. First, the current situation of rare research in this area in Brazil is presented, which is basically composed of anecdotes about how teachers organize their work with projects or of the advantages that this kind of work would bring to foreign language teaching and learning despite not having PBL as the main focus of their research and-perhaps for this reasonnot getting deep into this subject (WELP, 2011; KARNAL, 2013; PERUCHI, 2014; TUMOLO, 2015). Furthermore, there are other works which have PBL as their main focus, though they are based on works that don't deal with the subject specifically for the area of foreign language teaching (LEFFA; IRALA, 2014) or just begin to present some reference from the field (PESSOA, 2006). Then, the history of PBL and its characteristics in education in general are shown (DEWEY, 1910; KILPATRICK, 1918; HERNÁNDEZ, 1998; ANTUNES, 2001; NOGUEIRA, 2001; FRANCO, 2008; NOGUEIRA, 2008; BENDER, 2014) and afterwards the characteristics and concepts in the particular field of foreign language teaching and learning and its benefits to teaching in this area in present day are discussed. (FRIED-BOOTH, 1982; STOLLER, 1997; BECKETT, 1999; EYRING, 2001; BECKETT, 2002; FRIED-BOOTH, 2002; BECKETT, 2005; BECKETT; SLATER, 2005; BECKETT; MILLER, 2006).

\footnotetext{
${ }^{1}$ Trabalho originado de tese de doutorado em andamento sob orientação da $\operatorname{Prof}^{\mathrm{a}}$ Dr $^{\mathrm{a}}$ Clarissa Menezes Jordão.

${ }^{2}$ Bolsista de doutorado da Coordenação de Aperfeiçoamento de Pessoal de Nível Superior (CAPES).
} 
KEYWORDS: Project Based Learning; foreign language learning and teaching; foreign language teaching methodology.

\section{Introdução}

O objetivo deste trabalho é apresentar a Aprendizagem Baseada em Projetos (ABP) como abordagem para o ensino-aprendizagem de línguas estrangeiras. De início, o trabalho apresenta a situação atual da pesquisa nesta área no exterior e também no Brasil, passando então para um histórico da ABP e suas características na educação em geral e depois as características e conceitos no campo específico do ensino-aprendizagem de línguas estrangeiras, além de seus benefícios para o ensino nesta área na atualidade, bem como desvantagens em relação à sua utilização.

\section{Situação da pesquisa sobre ABP no Brasil}

Apesar de haver movimentos de pesquisa relacionados ao tema da ABP no país, como se pode ver em pesquisas acadêmicas dos últimos anos realizadas em áreas como ensino de geografia (GOULART, 2011), de ciência da computação (BRASIL, 2012), ciências da natureza (PADILHA, 2011) e ensino superior em geral (HAMERMULLER, 2011), especificamente em relação ao ensino-aprendizagem de língua inglesa ou línguas estrangeiras, as investigações têm sido raras. Este fato foi observado internacionalmente há mais de uma década por Beckett (2002) que afirmou então que

Comparada com a educação em geral, a pesquisa sobre projetos de trabalho em segunda língua é rara. A maioria da literatura disponível consiste de relatos casuais de como professores de línguas organizaram o trabalho com projetos com o propósito de aquisição de segunda língua ${ }^{3}$ (p. 58, tradução livre minha como as outros deste trabalho).

O mesmo cenário apontado por Beckett (2002) foi atestado mais tarde aqui no país por Pazello (2005).

Tal situação mudou um pouco a partir do ano de 2006, ao menos fora do Brasil, quando da publicação do volume "Project-based second and foreign language education: past, present, and future" (BECKETT; MILLER, 2006) que teve como intuito gerar uma discussão sistemática do trabalho da Aprendizagem Baseada em Projetos (ABP) na educação de segunda língua e língua estrangeira ao reunir trabalhos representativos, identificando lacunas de pesquisa e orientando o campo a direções futuras.

A publicação da reunião de trabalhos sobre o tema citado acima foi o início de uma preocupação mais acentuada em relação ao assunto, contudo, logo no prefácio do livro Van Lier (2006) afirma que apesar de o volume apresentar trabalhos que tratam da questão crucial da pesquisa empírica (tanto quantitativa quanto qualitativamente) dos efeitos e condições da $\mathrm{ABP}$, ele afirma que esta área de pesquisa vai precisar de muita atenção e esforço adicional no futuro.

\footnotetext{
${ }^{3}$ Compared with general education, research on project-based work in L2 education is rare. Most of the available literature consists of anecdotal reports of how language teachers organize their work for the purpose of second language acquisition.
} 
Voltando ao contexto específico da aprendizagem de línguas estrangeiras no país, pode-se encontrar trabalhos que tangenciam a $\mathrm{ABP}$, mas que não têm tal abordagem como foco. Alguns destes trabalhos são os de Welp (2011), que trata da construção de um programa de disciplina de inglês para um curso de Letras, de Karnal (2013), sobre o uso de e-board para o ensino de inglês, de Peruchi (2014), a respeito da internet como ferramenta para o ensino de língua inglesa e o trabalho de Tumolo (2015) sobre histórias digitais para o ensino de inglês.

Um trabalho que apresenta a ABP como um de seus focos principais é o de Leffa e Irala (2014), que, apesar disto, não leva em conta a literatura já produzida a respeito do tema no âmbito do ensino de línguas estrangeiras, recorrendo, ao invés disso, a autores que tratam de outras abordagens (e.g. Webquest, uso de vídeo) para desenvolver sua visão de pedagogia de projetos.

O trabalho que mais deu atenção à literatura a respeito do tema da ABP para seu trabalho com o ensino de língua inglesa foi Pessoa (2006) que tratou especificamente de sua experiência cm projetos de aprendizagem em aulas de língua inglesa no Ensino Superior.

Parece ser importante levar em conta a história da ABP quando se pretende utilizar tal abordagem para o ensino de línguas estrangeiras, com o fim de saber como tal abordagem se desenvolveu e escolher a maneira de proceder, baseada no que já foi experimentado, algo que não tem sido feito de maneira consistente no contexto nacional.

\section{Histórico da ABP}

A Aprendizagem Baseada em Projetos não é uma abordagem nova, tendo sua origem remontada aos trabalhos de John Dewey por vários autores (HERNÁNDEZ, 1998; BECKETT, 2002; 2006; VAN LIER, 2006; FRANCO, 2008; BENDER, 2014).

A este respeito, Beckett (2002) afirma que a instrução baseada em projetos foi primeiramente concebida para o ensino de aulas de agricultura nos EUA pelo especialista em eficiência David Snedden, sendo depois desenvolvida e popularizada entre professores pelo pupilo de John Dewey, William Heard Kilpatrick, principalmente por meio de seu panfleto "The Project Method" (KILPATRICK, 1918) considerado uma reconstrução do método baseado em problemas de Dewey. O método baseado em problemas pedia um aprendizado a partir da experiência em se resolver problemas do mundo real, sendo visto como uma alternativa à maneira tradicional de ensino-aprendizagem centrada no professor.

Apesar de van Lier (2006) colocar o início deste tipo de trabalho com Dewey no início do séc. $\mathrm{XX}$, ele defende que o movimento de reforma nos Estados unidos iniciado por Dewey e posteriormente com Kilpatrick seria similar de várias maneiras a reformas educacionais anteriores propostas no continente europeu, em especial as recomendações baseadas em ação, experiência e percepção que já haviam sido feitas no séc. XVII por Comenius, mais tarde no séc. XIX por Pestalozzi e por Maria de Montessori e Jean Piaget no início do séc. XX, além de Vygotsky. Assim, dada à variada, mas pedagogicamente convergência de seus antecedentes, van Lier (2006) não vê a ABP como mais uma moda que vá desaparecer como tantas outras reformas e metodologias do passado.

No que se refere ao campo particular da educação de segunda língua, a instrução baseada em projetos foi introduzida, de acordo com Beckett (2002), em resposta às inadequações percebidas a respeito da hipótese do input de Krashen (1981) na qual o teórico defendia que o input compreensível é a variável mais importante na aquisição de segunda língua, alegando 
que os aprendizes precisam de exposição extensiva na língua-alvo, como é o caso das crianças quando aprendem sua primeira língua. Contudo, se percebeu que somente a exposição ao input não era suficiente para a aquisição de uma segunda língua, sendo considerada também importante a produção de output compreensível por meio de interação, sendo necessárias variadas oportunidades comunicativas onde se pudesse engajar em negociações e interações significativas. Esta mudança de perspectiva, segundo a autora, foi evidenciada na obra de Brumfit "Communicative Methodology in Language Teaching" de 1984 que se utilizou de uma abordagem baseada em projetos. Por esta razão a instrução baseada em projetos tem sido aplicada para fornecer aos estudantes de segunda língua oportunidades de interação e comunicação na língua-alvo em contextos autênticos, ou seja, dar aos alunos a oportunidade de reciclar a língua e as habilidades conhecidas e usá-las em contextos naturais (BECKETT, 2002; 2006).

Além do foco na produção de output compreensível, Beckett (2006) afirma que mais recentemente a instrução baseada em projetos tem sido anunciada como uma abordagem apropriada para educação de segunda língua baseada em conteúdos (STOLLER, 1997), ensino de inglês para fins específicos (FRIED-BOOTH, 2002), socialização linguística baseada em comunidade (EYRING, 2001) e habilidades de pensamento de ordem superior e resolução de problemas (BECKETT, 2005).

No campo teórico, Beckett (2006) afirma que os trabalhos sobre ABP na educação de segunda língua e língua estrangeira abrangem numerosas áreas. Em um nível geral a $\mathrm{ABP}$ foi referida como uma abordagem educacional linguística que reflete a aprendizagem centrada no aluno (FRIED-BOOTH, 2002), dentro do esquema da aprendizagem experiencial (EYRING, 2001), e da autonomia do aluno (FRIED-BOOTH, 2002), e também da aprendizagem cooperativa e do pensamento crítico. Em um nível mais específico foi descrita como uma abordagem que promove o input e o output compreensíveis com ênfase na prática de habilidades de compreensão e produção oral, como citado anteriormente, e como uma abordagem baseada em conteúdo.

Através da história levantada até, vários autores se referiram a abordagens com características muito similares com diferentes denominações.

\section{Denominações}

No que diz respeito à nomeação da abordagem educacional baseada em projetos, Beckett (2002) alerta para o fato de haver, tanto na literatura sobre educação em geral quanto sobre educação de segunda língua, vários termos que se atribuem a atividades similares, como instrução baseada em projetos (que a própria autora mais utiliza), trabalho por projetos, método de projetos, abordagem por projetos, abordagem orientada por projetos e aprendizagem baseada em projetos. Podemos também observar outros termos para nomear atividades parecidas, como é o caso de projetos de trabalho (HERNÁNDEZ, 1998), projetos de aprendizagem (PESSOA, 2006; JORDÃO, 2011) e pedagogia de projetos (NOGUEIRA, 2001; PAZELLO, 2005; NOGUEIRA, 2008; WELP, 2011). Bender (2014) acrescenta ainda à lista os termos aprendizagem baseada em problemas, aprendizagem investigativa, aprendizagem autêntica e aprendizagem por descoberta.

Não obstante tal multiplicidade de nomes para conceber atividades fundamentalmente semelhantes, Van Lier (2006) defende que todas estas abordagens remontariam aos movimentos de reforma europeus e norte-americanos a partir dos trabalhos de Comenius, Pestalozzi, Maria de Montessori, Jean Piaget, Vygotsky, Dewey, Kilpatrik e seus seguidores e 
outros pesquisadores que introduziram abordagens holísticas da educação formando a base do que hoje muitos educadores de língua praticam sob os variados nomes como os citados anteriormente, incluindo ainda a aprendizagem baseada em ação, aprendizagem experiencial, ensino exploratório, ensino holístico, métodos humanísticos, e assim por diante. Van Lier (2006) defende que todas estas abordagens fluem do mesmo poço ideológico e pedagógico.

Mas o que todas estas atividades de diferentes nomes apresentam em comum? Alguns autores procuraram dar definições e apontar características que deem conta do que é a $\mathrm{ABP}$ e também, do que é projeto neste contexto de ensino.

\section{Definições e características da ABP}

Grande parte das abordagens citadas até aqui tem o projeto como elemento principal. Beckett (2002) define projeto como uma atividade de longo prazo (várias semanas) que envolve uma variedade de tarefas individuais e cooperativas como desenvolver um plano e perguntas de pesquisa e implementar tal plano através de pesquisa empírica ou documental que inclui coletar, analisar e relatar dados oralmente ou de maneira escrita.

Outro autor que apresenta uma definição para projeto é Nogueira (2008) que, em sua tentativa, expõe certa ambivalência em relação ao termo, já que o coloca como "uma irrealidade que vai se tornando real, conforme começa a ganhar corpo a partir de ações e, consequentemente, as articulações destas (p. 30)". Assim, o projeto é antecedido de ideias ou sonhos e só se faz presente quando começa a se concretizar a partir de ações. Por outro lado, o projeto "existe quando realizado, quando materializamos as intenções, mas a partir disso deixa de existir como projeto, já que não será mais um sonho, um desejo, algo 'lançado para diante' e sim algo real e já concebido (p. 31)”.

Quanto aos seus elementos, os projetos apresentam muitos em comum, de acordo com Bender (2014). Para o autor, as próprias tarefas de projeto variam de maneira considerável, entretanto, quase todos os projetos de $\mathrm{ABP}$ se concentram em questões ou problemas autênticos do mundo real, sendo esse foco nas experiências de aprendizagem autênticas, em tarefas que os estudantes podem ser solicitados a realizar no mundo real, uma característica de quase todas as experiências de ABP e este aspecto aumentaria ainda a motivação dos alunos para participarem ativamente dos projetos.

Outro elemento em comum entre os projetos seria o fato de a maioria das tarefas de $\mathrm{ABP}$ exigir um amplo trabalho cooperativo, já que segundo Bender (2014) os estudantes precisam planejar de maneira colaborativa as ações do seu grupo à medida que avançam na solução do problema. Além disso, o pesquisador afirma que a pesquisa e desenvolvimento de produtos e artefatos que são propostos nos projetos podem levar muitos dias, envolvendo a criação desde apresentações multimídia até um modelo de testes para o projeto ou problema.

Agora, no que diz respeito à definição da atividade ou abordagem de ensino-aprendizagem que utiliza tais projetos para atingir sua finalidade pedagógica, Bender (2014) a concebe como "um modelo de ensino que consiste em permitir que os alunos confrontem as questões e os problemas do mundo real que consideram significativos, determinando como abordá-los e, então, agindo cooperativamente em busca de soluções" (p. 9).

Outra definição de Bender (2014) para a ABP é a "utilização de projetos autênticos e realistas, baseados em uma questão, tarefa ou problema altamente motivador e envolvente, para ensinar 
conteúdos acadêmicos aos alunos no contexto de trabalho cooperativo para a resolução de problemas" (p. 15).

Apesar dos inúmeros termos levantados anteriormente utilizados para a abordagem de ensino de que se trata aqui, Bender (2014) defende que

a abordagem de ensino geral permanece a mesma: os alunos identificam e buscam resolver problemas do mundo real que consideram importantes, além de desenvolver vários projetos [...] que podem ser usados para demonstrar seus conhecimentos e comunicar sua resolução de problemas aos demais (p. 16).

Ao tratar da ABP no campo do ensino-aprendizagem de línguas estrangeiras, Beckett (2002) segue uma linha similar à de Bender (2014) ao defender que o método de projetos envolve estudantes que criam conhecimento a fim de solucionar problemas que surgem enquanto estão entretidos em atividades significativas do mundo real.

Outra autora da área de ensino-aprendizagem de línguas estrangeiras que traz uma definição da abordagem que utiliza projetos apresentando suas características é Fried-Booth (2002). Para ela:

[O] trabalho com projetos é centrado no estudante e guiado pela necessidade de criar um produto final. Contudo, é a rota para se chegar a este produto final que faz o trabalho com projetos valer a pena. A rota para o produto final traz oportunidades para os estudantes desenvolverem sua confiança e independência e trabalharem conjuntamente em um ambiente do mundo real ao colaborarem em uma tarefa da qual eles mesmos definiram e que não foi imposta externamente ${ }^{4}$. (p. 6)

Desta forma, o que mais caracteriza a ABP para a autora parece ser o processo para se chegar ao produto final.

Mais um trabalho que trata das particularidades do ensino-aprendizagem por meio de projetos é o de Stoller (1997) que faz um apanhado de características principais do trabalho por projetos que encontrou em diversos autores que tratam do assunto. Uma destas características seria o fato de que o trabalho por projetos focaria no aprendizado de conteúdo ao invés de objetivos linguísticos específicos.

Outro aspecto importante do trabalho com projetos seria o fato de ele ser cooperativo ao invés de competitivo. Neste tipo de contexto, os alunos podem trabalhar por conta própria, em pequenos grupos ou como turma para completar um projeto, compartilhando recursos, ideias e competências pelo caminho (STOLLER, 1997).

Além disso, o trabalho com projetos levaria a uma integração autêntica de habilidades e processamento de informação de fontes variadas, espelhando tarefas do mundo real. $\mathrm{O}$ trabalho por projetos seria também potencialmente motivador, estimulante, empoderador e

\footnotetext{
4 " [p]roject work is student-centred and driven by the need to create an end-product. However, it is the route to achieving this end-product that makes project work so worthwhile. The route to the end-product brings opportunities for students to develop their confidence and independence and to work together in a real-world environment by collaborating on a task which they have defined for themselves and which has not been externally imposed.
} 
desafiador. Ele resultaria assim na construção de confiança e autoestima do estudante, além de melhorar suas habilidades linguísticas, aprendizado de conteúdo e capacidades cognitivas (STOLLER, 1997).

Mais um aspecto fundamental neste tipo de trabalho de acordo com Stoller (1997) seria a centralidade no aluno, apesar de o professor representar um papel importante oferecendo suporte e direção durante todo o processo. A respeito deste papel importante do professor, de acordo com Nogueira (2008) ele seria o de mediador e facilitador já que:

[...] é ele quem "gerencia" o processo, oferecendo meios, questionando sobre possibilidades, incentivando o aprofundamento, oferecendo auxílio quando necessário, vibrando com os alunos diante de novas descobertas e até mesmo "direcionando" (no bom sentido da palavra) para aquele caminho que sua experiência julga ser o mais pertinente para o dado momento (p. 78).

Mais tarde, Stoller (2006) refletiu que devido a esta versatilidade que a aprendizagem baseada em projetos apresenta, fica difícil articular uma única definição que leve em conta as várias maneiras que o conceito pode ser traduzido na prática. Em vista disso, a autora propõe uma espécie de definição em forma de lista das numerosas condições que deveriam estar presentes para que a aprendizagem baseada em projetos aconteça. Assim, a aprendizagem baseada em projetos deveria:

(a) ter uma orientação direcionada ao processo e ao produto; (b) ser definida, pelo menos em parte, pelos estudantes, para encorajar a propriedade do aluno no projeto; (c) se estender por um período de tempo (ao invés de uma única aula); (d) encorajar a integração natural das habilidades; (e) ter um comprometimento duplo com o aprendizado de conteúdo e também linguístico; (f) exigir que os estudantes trabalhem em grupos e individualmente; (g) requerer dos alunos que tomem alguma responsabilidade pela própria aprendizagem por meio de coleta, processamento e relato de informações de recursos da língua alvo; (h) requerer a professores e alunos que assumam novos papéis e responsabilidades [...]; (i) resultar em um produto final tangível; e (j) concluir com reflexões do estudante a respeito tanto do processo quanto do produto $^{5}$ (STOLLER, 2006, p. 24).

Os autores citados neste trabalho que tratam e defendem o uso da $\mathrm{ABP}$ apontam os benefícios para tal utilização.

\section{Vantagens e benefícios do uso da ABP}

No que diz respeito às vantagens e benefícios do ensino-aprendizagem que utilizam projetos, Nogueira (2008) defende que tal trabalho pode gerar autonomia nos alunos, pois os faz

\footnotetext{
5 (a) have a process and product orientation; (b) be defined, at least in part, by students, to encourage student ownership in the project; (c) extend over a period of time (rather than a single class session); (d) encourage the natural integration of skills; (e) make a dual commitment to language and content learning; (f) oblige students to work in groups and on their own; (g) require students to take some responsibility for their own learning through the gathering, processing, and reporting of information from target language resources; (h) require teachers and students to assume new roles and responsibilities [...]; (i) result in a tangible final product; and (j) conclude with student reflections on both the process and the product.
} 
"decidir sua própria trajetória, seu próprio caminhar e optar pela sua própria tecedura de significados em sua rede (p.47)".

Além disso, de acordo com o autor:

As flexibilizações pedagógicas imbrincadas na prática do trabalho com projetos permitem o posicionamento do aluno quanto: ao planejamento, às ações, às escolhas, às oportunidades, às trajetórias, etc., as quais são situações propensas às tomadas de decisões, o que não poderá ocorrer sem a prática da livre escolha, ou seja, da autonomia (NOGUEIRA, 2008, p. 47).

Outras vantagens em se trabalhar com projetos temáticos para Nogueira (2008) seriam o fato de propiciar maior interação entre alunos, facilitar o trabalho com a concepção de conhecimento por redes de significado, possibilitar o atendimento às diferentes formas de aprendizado dos alunos e auxiliar no desenvolvimento do espectro de competências e auxiliar no desenvolvimento da autonomia, da criatividade, das relações interpessoais e do espírito de cooperatividade, da facilidade de aceitar desafios, resolver problemas, estabelecer conexões, etc.

Além disso, o trabalho com projetos levaria o aluno

a enxergar relações além das disciplinas de tal forma a interpretar o mundo, a realidade e a sociedade na qual estão inseridos. Um olhar mais voltado à complexidade da vida e do mundo, um olhar mais holístico e transdisciplinar com relação ao conhecimento, além dos conteúdos das disciplinas acadêmicas (NOGUEIRA, 2008: 53).

Ainda no que se refere às vantagens da aplicação do ensino-aprendizagem baseado em projetos, Bender (2014) defende que ele tem se mostrado uma abordagem eficaz que envolve e desenvolve os alunos em alto nível por meio de enfrentamento de questões e problemas do mundo real que consideram significativos e por isso tem sido recomendada por muitos defensores da educação. O autor acrescenta que a ABP "é uma das mais eficazes formas de envolver os alunos com o conteúdo de aprendizagem" (p. 15) e que a Aprendizagem Baseada em Projetos seria "um formato de ensino empolgante e inovador, no qual os alunos selecionam muitos aspectos de sua tarefa e são motivados por problemas do mundo real que podem, e em muitos casos irão, contribuir para sua comunidade (p. 15)"”.

Além disso, Bender (2014) afirma que devido às alterações no processo de ensino acarretadas pelas novas tecnologias, a ABP parece bem posicionada para se tornar o principal modelo de ensino do século, recomendando assim sua aplicação.

A este respeito, van Lier (2006) defende que a ABP não é somente uma maneira diferente e mais eficiente para possibilitar oportunidades de aprendizado de línguas, mas é também de maneira mais ampla como uma empreitada semiótica-ecológica que se concentra na confecção e uso de signos que são multissensoriais e multimodais sendo que as habilidades perceptuais não devem ser deixadas de lado, elas devem ser promovidas, orientadas e praticadas a fim de facilitar o funcionamento em contextos relevantes.

Mais vantagens da abordagem baseada em projetos são apresentadas por Beckett (2002) que afirma que tanto a literatura em educação em geral e de segunda língua em específico listam vários benefícios para esta prática. Os maiores benefícios listados na educação em geral seriam as oportunidades que ela fornece para os estudantes em relação à motivação intrínseca 
para aprender, fomentando a solução de problemas e desenvolvendo habilidades de trabalho independente e cooperativa. Também se acredita que este tipo de instrução permite aos estudantes desenvolver o pensamento crítico e as habilidades de tomada de decisão e se engajar no aprendizado profundo de assuntos.

Já na literatura de segunda língua, a autora aponta que há menções ocasionais de que a instrução baseada em projetos estimularia habilidades analíticas e administrativas, mas a ênfase principal nesta área é na oportunidade que o trabalho por projetos fornece para a produção de output compreensível, conforme mencionado anteriormente (BECKETT, 2002).

Já para Pessoa (2006), os projetos de aprendizagem de língua se apresentam como uma maneira de combater a passividade dos aprendizes. Para ela, um aspecto que mudou do ensino tradicional para o contemporâneo do ensino de línguas foi o papel do aluno. Assim, a autora propôs projetos de aprendizagem de língua para que os alunos se tornassem mais ativos e independentes em seus estudos.

Os autores que tratam da $\mathrm{ABP}$ não veem, porém, somente pontos positivos ou facilidades em sua implantação.

\section{Desvantagens e críticas à implantação da $\mathrm{ABP}$}

Apesar de tantas vantagens e benefícios que os autores que tratam da ABP apresentam, ainda há dificuldades ou mesmo confusão na implantação de tal abordagem de ensino. Nogueira (2008), por exemplo, critica trabalhos que se veem em escolas que são projetados pela coordenação pedagógica que decide o tema ou objeto de investigação, os objetivos, as estratégias e ações a serem tomadas pelos alunos. Em um caso como este, indaga o autor, como a coordenação pedagógica poderia vislumbrar as necessidades e interesses dos alunos que executarão o projeto? Ademais, seria possível os alunos "sonharem" os sonhos da coordenação pedagógica?

Ainda a respeito das dificuldades enfrentadas por tal tipo de trabalho, van Lier (2006) chama atenção para o fato das fronteiras, limites, sanções, proibições e restrições que são colocadas na implementação da ABP e de outras abordagens similares no mundo real e cotidiano da educação institucional. $\mathrm{O}$ autor argumenta, por exemplo, que os trabalhos com projeto estão presentes no início da vida escolar, no jardim de infância, e vão desaparecendo à medida que o aluno avança para a escola secundária e período preparatório para a faculdade. Assim que os estudantes atingem o ápice da educação formal, na pós-graduação, os projetos se tornam proeminentes novamente, mas eles já não se lembram mais de como era trabalhar daquela maneira há tantos anos no ensino infantil e assim adaptações dolorosas são necessárias.

Em vista disso, van Lier (2006) afirma que de certa forma todos os estudantes têm contato com a ABP durante sua vida escolar, mais no começo da educação fundamental e depois esparsamente em projetos de ciência como os das feiras de ciências durante o ensino de nível secundário e terminando para aqueles que insistem até o fim na "mãe de todos os projetos", a tese de doutorado. Desta forma, o autor afirma que todos os alunos e professores têm certa familiaridade com o trabalho com projetos, apesar de eles serem complementares, serem meramente uma adição ao conteúdo regular ou ao currículo orientado por fatores linguísticos. Ademais, segundo o autor, ainda continuam raros os currículos que têm os projetos como princípio orientador principal. 
Além disso, van Lier (2006) chama atenção para o fato de que a ABP é geralmente utilizada em cursos elitistas em que não há perspectiva de notas altas e que não tornam os estudantes bem sucedidos nem os impede de atingir tal objetivo. Assim, sempre que testes padronizados que definem o futuro dos estudantes (como seria o caso dos nossos vestibulares ou o ENEM) estão em jogo, iniciativas como a ABP tendem a serem tiradas de cena. Esta é uma crítica frequentemente recebida por instituições de ensino que utilizam métodos de ensino com projetos, como é o caso da Escola da Ponte em Portugal, fato que pode ser observado na preocupação de uma mãe que gostaria de matricular sua filha em uma escola mais "criativa": "Será que o aluno da Ponte quando for enfrentar o secundário, o vestibular, o 'mundo padrão' não se sentirá fora, inadequado? (PACHECO; PACHECO, 2015: 98)".

Nesse contexto, Van Lier (2006) aponta para o ambiente político e institucional no qual a ABP deve encontrar seu lugar indicando duas tendências ou temas que formam as políticas educacionais da maioria dos governos: uma é criar uma força de trabalho que seja flexível, adaptável e criativa para as mudanças do ambiente de trabalho e que seja capaz de aprender durante a vida inteira; a outra é controlar, prescrever e prever o que entra e sai dos estabelecimentos educacionais. A ironia, segundo o autor, é que um tema é completamente incompatível com o outro. É como se os governos estivessem abrindo a porta com uma mão enquanto a fecham com a outra.

Devido aos fatores apontados, van Lier (2006) afirma que a ABP tende a acontecer na periferia da paisagem educacional. $\mathrm{O}$ autor adverte que devemos ter em mente que em um clima educacional governado pela tríade dos padrões-responsabilidade por resultados-testes há uma pressão cada vez maior de se remover do currículo tudo que não alimente diretamente notas de provas em leitura e matemática. Este tipo de perspectiva educacional sufocaria a criatividade.

Apesar das dificuldades de implantação da ABP, levando-se em conta suas vantagens e benefícios, esta abordagem parece ser útil para o ensino de línguas estrangeiras o momento atual.

\section{Considerações finais}

Neste trabalho se buscou apresentar a abordagem da Aprendizagem Baseada em Projetos para o ensino-aprendizagem de línguas estrangeiras, em sua situação de pesquisa no país, seu histórico, suas diferentes formas de nomeação, definições e características, além de seus benefícios e vantagens e suas dificuldades de implantação.

Espera-se que a partir do exposto aqui, pesquisadores e professores que pretendam lidar com tal abordagem possam levar em conta o que já foi pesquisado e experimentado na área, não necessitando iniciar seus trabalhos sem uma base a que recorrer, tendo assim um maior poder de decisão e material para reflexão a respeito do tema.

\section{Referências}

BECKETT, G. H. Academic language and literacy socialization through project based instruction: ESL student perspectives and issues. Journal of Asian Pacific Communication, v. 15, n. 1, p. 191-206, 2005. 
Project-based second and foreign education: theory, research, and practice. In:

BECKETT, G.;MILLER, P. C. Project-based second and foreign education: past, present, and future. Greenwich: Information Age Publishing, 2006. p. 3-16.

Teacher and student evaluations of project-based instruction. TESL Canada Journal, v. 19, n. 2, p. 52-66, 2002.

BECKETT, G. H.; MILLER, P. C. (ed.). Project-based second and foreign language education: past, present, and future. Greenwich: Information Age Publishing, 2006.

BENDER, W. N. Aprendizagem baseada em projetos: educação diferenciada para o século XXI. Porto Alegre: Penso, 2014.

BRASIL, I. S. ATEP: um jogo 3D persistente baseado em navegador para apoiar a aprendizagem baseada em projetos de operadores de sondas de perfuração de poços de petróleo terrestres. Dissertação (Mestrado em Ciência da Computação), Universidade do Estado do Rio Grande do Norte, Mossoró, 2012.

EYRING, J. L. Experiential and negotiated language learning. In: CELCE-MURCIA, M. Teaching English as a second or foreign language. 3 ed. Boston: Heinle, 2001. p. 333-344.

FRANCO, E. K. Currículo por projetos: inovação no ensinar e aprender na educação superior. Dissertação (Mestrado em Educação), Pontifícia Universidade Católica de São Paulo, São Paulo, 2008.

FRIED-BOOTH, D. Project Work. 2 ed. New York: Oxford University Press, 2002.

GOULART, L. B. Alunos e professores fazendo geografia: a rede ressignificando informações. Tese (Doutorado em Geografia), Universidade Federal do Rio Grande do Sul, Porto Alegre, 2011.

HAMERMULLER, D. O. Possibilidades e limites do exercício da autonomia dos estudantes na UFPR Litoral: os projetos de aprendizagem em foco. Dissertação (Mestrado em Educação), Universidade Federal do Paraná, Curitiba, 2011.

HERNÁNDEZ, F. Transgressão e mudança na educação: os projetos de trabalho. Artmed, 1998.

JORDÃO, C. Epistemofagia transformadora: saberes locais e inclusão no ensino superior brasileiro. Educação em Revista, v. 27, n. 2, p. 249-276, 2011.

KARNAL, A. R. O uso do e-board no ensino de inglês como L2/LF. Texto Livre, v. 6, n. 2, p. 56-66, 2013.

KILPATRICK, W. H. The project method. Teachers College Record, v. 19, n. 1, p. 319-335, 1918.

KRASHEN, S. Second language acquisition and second language learning. Oxford: Pergamon Press, 1981. 
LEFFA, V. J.; IRALA, V. B. O ensino de outra(s) língua(s) na contemporaneidade: questões conceituais e metodológicas. In: LEFFA, V. J.; IRALA, V. B. Uma espiadinha na sala de aula: ensinando línguas adicionais no Brasil. Pelotas: Educat, 2014. p. 21-48.

NOGUEIRA, N. R. Pedagogia dos projetos: uma jornada interdisciplinar rumo ao desenvolvimento das múltiplas inteligências. 6. ed. São Paulo: Érica, 2001.

Pedagogia dos projetos: etapas, papéis e atores. 4. ed. São Paulo: Érica, 2008. PACHECO, J.; PACHECO, M. A avaliação da aprendizagem na Escola da Ponte. Rio de Janeiro: Wak, 2012.

PADILHA, C. J. Análise da utilização de projetos de aprendizagem no ensino de ciências da natureza nos anos iniciais das escolas municipais do município de Boa Vista - RR. Dissertação (Mestrado em Ensino de Ciências e Matemática), Universidade Luterana do Brasil, Canoas, 2011.

PAZELLO, E. Pedagogia de projetos e o ensino de inglês como língua estrangeira moderna em escola regular de $5^{\mathbf{a}}$ a $8^{\mathbf{a}}$ séries: convicção ou modismo? Dissertação (Mestrado em Letras), Universidade Federal do Paraná, Curitiba, 2005.

PERUCHI, R. "Just google it": a internet como ferramenta metodológica complementadora do livro didático para o desenvolvimento do foco na forma em wh-questions. Educação, Artes e Inclusão, v. 9, n. 1, p. 147-164, 2014.

PESSOA, R. R. Análise de uma experiência de sala de aula com projetos de aprendizagem de língua. the ESPecialist, v. 27, n. 2, p. 147-168, 2006.

STOLLER, F. Establishing a theoretical foundation for project-based learning in second and foreign language contexts. In: BECKETT, G. H.;MILLER, P. C. Project-based second and foreign language education: past, present, and future. Greenwich: Information Age Publishing, 2006. p. 19-40.

Project Work: a means to promote language content. English Teaching Forum, v. 35, n. 4, p. 2-9, 37, 1997.

TUMOLO, C. H. S. Histórias digitais como recurso para ensino/aprendizagem de inglês como língua estrangeira. Estudos Anglo Americanos, v. 1, n. 43, p. 101-117, 2015.

VAN LIER, L. Foreword. In: BECKETT, G.;MILLER, P. C. Project-based second and foreign language education: past, present, and future. Greenwich: Information Age Publishing, 2006. p. xi-xvi.

WELP, A. K. D. S. Construção de programa de disciplina de língua inglesa para o curso de graduação em Letras. Cadernos do IL, v. único, n. 42, p. 64-82, 2011. 